\title{
Mapping of Photoperiod-induced Growth Cessation in the Wild Grape Vitis riparia
}

\author{
Amanda Garris ${ }^{2}$, Lindsay Clark ${ }^{1}$, and Chris Owens \\ U.S. Department of Agriculture-Agricultural Research Service, Grape Genetics Research Unit, 630 \\ West North Street, Geneva, NY 14456 \\ Steven McKay and James Luby \\ Department of Horticultural Sciences, University of Minnesota, 342 Alderman Hall, 1970 Folwell \\ Avenue, St. Paul, MN 55413 \\ Kathy Mathiason and Anne Fennell \\ Department of Horticulture, Forestry, Landscape, and Parks, South Dakota State University, NPB \\ 201, Box 2140A, Brookings, SD 57007
}

\begin{abstract}
AdDitional INDEx wORDs. QTL, endodormancy, lateral buds, microsatellite, SSR
Abstract. In grapevines (Vitis spp.), the timing of growth cessation in the fall is an important aspect of adaptation and a key objective in breeding new grape cultivars suitable for continental climates. Growth cessation is a complex biological process that is initiated by environmental cues such as daylength and temperature, as well as water and nutrient availability. The genetic control of growth cessation in grapevines was studied by mapping quantitative trait loci (QTL) in a hybrid grape population. An $F_{2}$ mapping population was developed by selfing a single $F_{1}$ plant derived from a cross between an accession of the North American species Vitis riparia and the Vitis hybrid wine cultivar Seyval (Seyve-Villard 5-276). A linkage map was constructed using 115 simple sequence repeat (SSR) markers and six candidate genes in a population of $119 \mathrm{~F}_{2}$ progeny. The markers provided coverage of the 19 Vitis linkage groups with an average distance between markers of $8.4 \mathrm{cM}$. The critical photoperiod for growth cessation in lateral buds for the parents and $F_{2}$ progeny was determined in a replicated field trial in 2001 and 2002 and under controlled photoperiod treatments in a greenhouse in 2002, 2003, and 2004. QTL analysis using composite interval mapping identified a single major QTL in the field and greenhouse trials. However, the field and greenhouse QTL mapped to different linkage groups in the two different environments, suggesting the presence of additional, nonphotoperiodic cues for induction of growth cessation in the field. In the greenhouse, where noninducing temperatures were maintained, a QTL on linkage group (LG) 13 explained $\mathbf{8 0 . 0} \%$ to $\mathbf{9 6 . 6} \%$ of the phenotypic variance of critical photoperiod for growth cessation. In the field, where vines experienced natural fluctuations in temperature and rainfall in addition to the naturally decreasing photoperiod, a QTL on LG 11 explained $85.4 \%$ to $94.3 \%$ of phenotypic variance.
\end{abstract}

\begin{abstract}
The Eurasian domesticated grape Vitis vinifera is adapted to areas with moderate winter temperatures. Breeding new grapevine cultivars for the continental climate of North America has required the combination of fruit quality traits from $V$. vinifera with adaptive genes from wild North American Vitis species to promote survival and productivity in regions with shorter growing seasons, colder midwinter temperatures, and greater variability in spring and fall conditions. Grapes have a seasonally indeterminate growth habit and are particularly vulnerable to early fall frosts; freezing temperatures in the fall before vines are fully cold-acclimated can result in bud death and trunk damage (Keller and Mills, 2007; Kovacs et al., 2003). Thus, the sensitivity to environmental cues that induce growth cessation is one critical aspect of adaptation to continental climates. A better understanding of the genetic control of growth cessation and the identification of associated molecular
\end{abstract}

Received for publication 2 Oct. 2008. Accepted for publication 24 Feb. 2009. We thank Ann Marie Connor and Ken Mullin for their assistance in data collection and Susan Brown and Judy Kolkman for providing critical reviews. The mention of a trademark name or proprietary product does not constitute a warranty or guarantee by the USDA nor does it imply the exclusion of other products that may also be suitable.

${ }^{1}$ Current address: Department of Plant Sciences, University of California, Davis, CA 95616.

${ }^{2}$ Corresponding author. E-mail: amanda.garris@ars.usda.gov. markers would facilitate breeding for adaptation to such climates.

In northern latitudes, woody plants undergo several gradual and concurrent developmental changes before the onset of winter, including growth cessation, dormancy induction, cold acclimation, and leaf senescence. Growth cessation requires the termination of cell division in apical and axillary meristems and suppression of internode elongation. Endodormancy suppresses bud growth, even under permissive environmental conditions. The physiological and metabolic changes associated with cold acclimation allow plant tissues to withstand colder temperatures without damage. The cessation of growth before leaf senescence redirects resources into acclimation processes and remobilizes nutrients from leaves to overwintering shoots and roots.

The control of growth cessation is complex and can be triggered in response to environmental cues, including light, temperature, and water status. Woody plant growth cessation commonly is induced by low, nonfreezing temperatures (2$6{ }^{\circ} \mathrm{C}$ ), which can also lead to endodormancy and cold acclimation. In apple (Malus pumila) and pear (Pyrus communis), low temperatures $\left(<12{ }^{\circ} \mathrm{C}\right)$ induce cold acclimation and dormancy (Heide and Prestrud, 2005). Induction of dormancy and cold acclimation by low temperatures also was reported in red osier dogwood (Cornus sericea), birch species (Betula spp.), and 
raspberry (Rubus idaeus) (Junttila et al., 2003; Palonen, 2006; Svendsen et al., 2007).

Some woody species contain an additional mechanism for induction of growth cessation through a pathway mediated by photoperiod sensitivity. Ecotypic variation for growth cessation in response to the decreasing photoperiods that occur in northern latitudes in late summer has been identified in black cottonwood (Populus trichocarpa) and birch (Betula pubescens, Betula pendula) (Howe et al., 1995; Junttila et al., 2003). Ecotypes from higher latitudes frequently initiate growth cessation in response to longer critical daylengths (the longest photoperiod that elicits a short-day response) than their southern counterparts, resulting in earlier cessation of growth (Frewen et al., 2000). Studies suggest that genetic control of photoperiodic induction of growth cessation is heritable and controlled by a small number of genes or quantitative trait loci (QTL) (Fennell et al., 2005; Frewen et al., 2000; Howe et al., 2000).

It may be challenging to decouple the effects of photoperiod and temperature on cold acclimation and dormancy induction, given that tree species may be responsive to both ( $\mathrm{Li}$ et al., 2002; Welling et al., 2002). It has been suggested that photoperiod and temperature work synergistically by acting on common downstream components such as hormones (Arora et al., 2003; Heggie and Halliday, 2005). Elucidation of the interplay between multiple environmental cues, the points of convergence on common downstream targets, and the effects on the timing of growth cessation and the depth of dormancy or cold hardiness will provide insight on the molecular basis of adaptation.

Grapevines are seasonally indeterminate and do not set a terminal bud at the shoot tip in the fall, the hallmark phenotype of most growth cessation studies in woody plants. Instead, the gradual process of growth cessation is marked by suspension of cane and summer lateral elongation, abscission of the meristematic shoot tip, induction of endodormancy in latent axillary buds, and eventual leaf senescence (Alleweldt and During, 1972; Wake and Fennell, 2000). Vitis labrusca and V. riparia contain photoperiod-sensitive ecotypes (Fennell and Hoover, 1991; Wolpert and Howell, 1986), although the most extreme photoperiod sensitivity is found in $V$. riparia, whose northern clones exhibit leaf senescence well before the first frost (Pierquet and Stushnoff, 1978). The genetic basis for this photoperiodic induction of growth cessation in grapevines is not known.

The objective of this study was to develop a map suitable for QTL analysis to identify regions of the genome associated with growth cessation in grapevine. Integrated grapevine maps provide a robust framework for the design of mapping studies (Doligez et al., 2006; Vezzulli et al., 2008). QTL analysis has been used successfully in grapevines to identify genomic regions associated with flavor, yield components, plant nutrition, and pest and disease resistance (Doucleff et al., 2004; Fanizza et al., 2005; Fischer et al., 2004). Several of the Vitis maps have incorporated wild grape species, either in crosses with $V$. vinifera or as crosses between wild species (Doucleff et al., 2004; Krivanek et al., 2006; Lowe and Walker, 2006).

The $\mathrm{F}_{2}$ mapping population for this study was derived from the cross $V$. riparia (USDA PI 588289) × 'Seyval' (Seyve Villard 5-276). 'Seyval' is a disease and a phylloxera resistant, relatively cold hardy hybrid wine cultivar derived from a complex hybridization of $V$. vinifera $(55 \%$ by pedigree) with wild species native to the south-central United States, Vitis rupestris, and Vitis aestivalis var. lincecumii. The $V$. riparia parent has a longer critical photoperiod $(\approx 13.5 \mathrm{~h})$ that confers earlier growth cessation and better midwinter cold hardiness than 'Seyval' (critical photoperiod $\approx 11 \mathrm{~h}$ ) (Fennell et al., 2005). The photoperiod response of the $F_{1}$ is intermediate to the parents. Photoperiod sensitivity in the $\mathrm{F}_{2}$, measured by growth cessation at the 12-h photoperiod indicates the trait is heritable and suggests the action of a single gene and dominance of the $V$. riparia photoperiod response (Fennell et al., 2005). In this study, the $\mathrm{F}_{2}$ progeny of $V$. riparia $\times$ 'Sevyal' were used to develop a linkage map of simple sequence repeat (SSR) markers to identify regions of the genome associated with growth cessation in the field and under controlled conditions in the greenhouse.

\section{Materials and Methods}

Population development. The $\mathrm{F}_{2}$ mapping population was generated by selfing a single $F_{1}$ derived from the cross $V$. riparia (USDA PI 588289) $\times$ Vitis hybrid 'Seyval' (Seyve Villard 5-276). The seedlings were grown one season in the greenhouse, induced into dormancy, cycled through storage $\left(4{ }^{\circ} \mathrm{C}\right)$, and returned to active growth. After one season's growth, the vines were clonally propagated on their own roots for field studies. The original potted vines were cycled seasonally between the greenhouse and $4{ }^{\circ} \mathrm{C}$ storage for controlled environment studies.

Phenotypic evaluation. In 2002, 2003, and 2004, $115 \mathrm{~F}_{2}$ plants were grown in climate-controlled greenhouses with an automated photoperiod system (Van Rijn Enterprises Greenhouse Systems, Grassie, ON, Canada) in Brookings, SD (lat. $44^{\circ} 19^{\prime} \mathrm{N}$ ) with $25 / 20 \pm 3{ }^{\circ} \mathrm{C}$ (day/night) temperatures. Four replicates of the $V$. riparia parent, 'Seyval', and the $\mathrm{F}_{1}$ were included as controls. All plants were cycled annually through dormancy in a cold room at $4{ }^{\circ} \mathrm{C}$ for at least $150 \mathrm{~d}$. Each spring, ecodormant plants were root pruned and repotted in 1:2:2 soil media (soil:peat:perlite by volume) to prevent root binding and to maintain uniform growth throughout the studies. Vines were grown in 15 -L pots at $25 / 20^{\circ} \mathrm{C}$ under a 15 -h photoperiod. Three shoots per plant were trained vertically on bamboo stakes. Plants were watered daily and fertilized twice weekly with a $200 \mathrm{mg} \cdot \mathrm{L}^{-1} 20 \mathrm{~N}-8.7 \mathrm{P}-16.6 \mathrm{~K}$ solution. Once the shoots reached 12 nodes, the photoperiod was decreased weekly by $0.5 \mathrm{~h}$ using the automated white-covered photoperiod system (Van Rijn Enterprises Greenhouse Systems). The automated photoperiod system blocked light pollution from adjacent greenhouses, providing uniform photoperiod control under controlled temperature conditions.

In addition, the parents, $F_{1}$, and $F_{2}$ progeny were clonally replicated on their own roots and were evaluated under field conditions (parents and $\mathrm{F}_{1}$, six replicates; $\mathrm{F}_{2}$, three replicates). The field planting of three replicates in a completely randomized design was established at the University of Minnesota Horticultural Research Center in Chanhassen, MN (lat. $44^{\circ} 59^{\prime} \mathrm{N}$ ) in Spring 2000. Plants were spaced $0.7 \mathrm{~m}$ apart in rows with $2 \mathrm{~m}$ between rows with a single trunk height of $1.5 \mathrm{~m}$. Plants were irrigated during the establishment year, but rainfall during the growing seasons was sufficient in 2001 (average 8.4 $\mathrm{cm} / \mathrm{month}$ ) and sufficient to excessive in 2002 (average 11.4 $\mathrm{cm} / \mathrm{month}$ ). In Winter 2001 and Winter 2002, vines were pruned back to spurs at $\approx 0.3 \mathrm{~m}$ above the ground. Although 
three full replicates of $104 \mathrm{~F}_{2}$ genotypes were initially planted, some plants died and others were damaged in one year; hence, data were collected on 93 genotypes in 2001 (223 plants) and 2002 (228 plants). For two genotypes, only one year of data were collected.

Surviving genotypes in the field $(n=93)$ were evaluated for growth cessation beginning in July when the shoots averaged 12 nodes. Growth was evaluated at each hour of natural decrease in photoperiod: $15 \mathrm{~h}$ (24 July), $14 \mathrm{~h}$ (17 Aug.), $13 \mathrm{~h}$ (6 Sept.), and $12 \mathrm{~h}$ (26 Sept.) in 2001 and 2002. In the greenhouse, all genotypes $(\mathrm{n}=115)$ were evaluated in 2002, 2003, and 2004 under simulated photoperiods at 15-, 14-, 13-, 12-, and 11-h daylengths (Fennell et al., 2005). Unlike the constant rate of artificial photoperiod decrease in the greenhouse $(1 \mathrm{~h}$ decrease every 2 weeks), the natural rate of photoperiod decrease varies in the field. Any vines still growing at the last photoperiod scored were assigned growth cessation for the next 1-h decline in photoperiod (i.e., $11 \mathrm{~h}$ in the field and $10 \mathrm{~h}$ in the greenhouse).

Growth cessation was evaluated by monitoring summer lateral emergence. Summer laterals are shoots that develop from the prompt bud in the axils of the leaves on most grape shoots; they grow in the same season in which they are formed (Fig. 1). Summer lateral emergence begins six to eight nodes below the shoot tip. Because cessation of lateral emergence was shown to be a reliable proxy for cessation of shoot elongation and induction of bud dormancy (Fennell et al., 2005), it was used as the measure of growth cessation. The number of nodes with a summer lateral with at least one fully expanded leaf was recorded at each hour decline in photoperiod. The critical photoperiod for growth cessation was defined as the photoperiod where no additional summer laterals with at least one fully expanded leaf were produced.

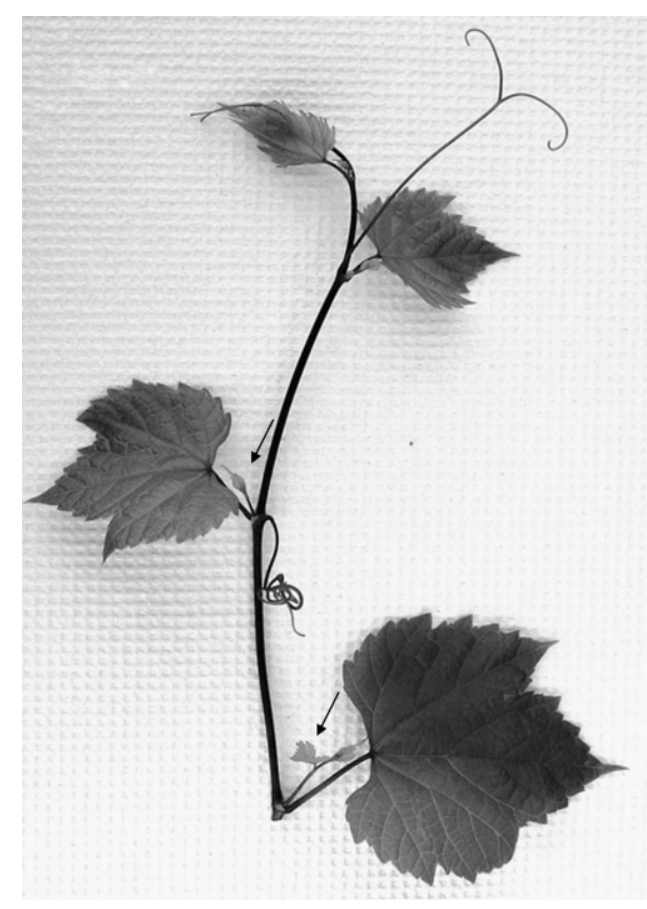

Fig. 1. Photograph of a growing shoot of Vitis riparia. Arrows indicate lateral shoots emerging from prompt buds.
Statistical analysis of PHenotypic Data. Analyses of variance (ANOVA) and product-moment (Pearson's) correlation analyses were performed on phenotypic data from greenhouse and field experiments using $\mathrm{R}$ statistical software ( $\mathrm{R}$ Development Core Team, 2007). For ANOVA of the greenhouse experiment, years and genotypes were considered fixed effects. For the field experiment, data were analyzed as a completely randomized design over years using years, genotypes, and interactions as fixed effects and also in individual years using genotypes as fixed effects. The correlations across years and across treatments (greenhouse vs. field) were assessed with Pearson's product-moment correlation analyses. Correlations between years in the field and in the greenhouse were estimated on an individual plant basis so that they were analogous. Correlations between field and greenhouse were estimated on a genotype basis.

LiNKAGE MAP CONSTRUCTION. DNA was extracted from the freeze-dried leaves of the mapping population of $119 \mathrm{~F}_{2}$ offspring using established protocols (Lin and Walker, 1997). Extracted DNA was quantified with Picogreen (Invitrogen, Carlsbad, CA) and diluted to $20 \mathrm{ng} \cdot \mu \mathrm{L}^{-1}$.

The $F_{1}$ was screened with 205 publicly available SSR markers to identify informative heterozygous loci (Supplemental Table 1 available online at www.ashs.org). Subsequently, up to four markers were multiplexed per PCR reaction for mapping in the $\mathrm{F}_{2}$ population. Forward primers were labeled with a fluorescent dye (FAM, HEX, TAMRA, VIC, PET, or NED). Multiplex PCR was carried out in $20-\mu$ L reactions that included $20 \mathrm{ng}$ of genomic DNA, 1 to 16 pmol of each forward and reverse primer, $200 \mu \mathrm{M}$ dNTP, $1 \times$ Taq polymerase buffer with $1.5 \mathrm{mM} \mathrm{MgCl}_{2}$, and $1 \mathrm{U}$ of Taq polymerase (Promega, Madison, WI). An i-Cyler (Bio-Rad, Hercules, CA) and a PTC100 (Bio$\mathrm{Rad})$ were used to perform the following amplification protocol: $4 \mathrm{~min}$ at $94{ }^{\circ} \mathrm{C}$; 35 cycles of $1 \mathrm{~min}$ at $94{ }^{\circ} \mathrm{C}, 30 \mathrm{~s}$ at annealing temperature, $30 \mathrm{~s}$ at $72{ }^{\circ} \mathrm{C} ; 1 \mathrm{~h}$ at $72{ }^{\circ} \mathrm{C}$. The long final extension time allows $\mathrm{Taq}$ to add an additional adenine to all fragments for consistency in automated allele scoring. Supplemental Table 1 contains information on multiplexes and experimentally determined annealing temperatures.

Following PCR amplification, PCR reactions were pooled; $1 \mu \mathrm{L}$ of the pooled products was combined with $10 \mu \mathrm{L}$ of Hi-Di formamide and $0.15 \mu \mathrm{L}$ of the internal size standard Genescan 500 LIZ (Applied Biosystems, Foster City, CA). Following denaturation for $4 \mathrm{~min}$ at $94{ }^{\circ} \mathrm{C}$, the samples were analyzed on an ABI3730 Genetic Analyzer (Applied Biosystems) at the Cornell Life Sciences Core Sequencing Laboratory (Ithaca, NY). Chromatogram analysis and allele-calling were performed with Genemapper 3.7 software (Applied Biosystems).

SEgRegation ANALYSIS AND MAP CONSTRUCTION. The linkage map was constructed with 120 SSR markers. The segregation of each marker in the $\mathrm{F}_{2}$ population was tested for goodness-of-fit using $\chi^{2}$ values from the Locus Genotype Frequency calculation in Joinmap 3.0 to identify departure from expected ratio of 1:2:1 (Van Ooijen and Voorrips, 2001). Distorted loci that did not disrupt the marker order were retained in the dataset. Recombination fractions between pairs of markers and map analysis were also performed with Joinmap 3.0. Markers were allocated to linkage groups with a minimum threshold logarithm of odds score (LOD) of 5.0 and a maximum recombination fraction of 0.40 using the Kosambi mapping function (Kosambi, 1943). The use of SSR markers from previously published grape genome maps allowed for direct identification 
Table 1. Sequences of primers used in mapping of candidate genes for growth cessation. Primers flank a polymorphism in the $\mathrm{F}_{1}$ of a cross between North American wild grape species Vitis riparia and the Vitis hybrid wine cultivar Seyval. The type variation targeted included single nucleotide polymorphisms (SNPs) and insertion-deletions (indels).

\begin{tabular}{|c|c|c|c|c|}
\hline Locus & Forward primer $\left(5^{\prime}-3^{\prime}\right)$ & Reverse primer $\left(5^{\prime}-3^{\prime}\right)$ & Type & $\begin{array}{c}\text { Scaffold in ML8X } \\
\text { genome (no.) }\end{array}$ \\
\hline$V v P H Y B$ & ACAACCATGTGAGCCAACAG & AAAATTCTTGTACTAAATCAAGCAAA & Indel & 64 \\
\hline$V v P H Y E$ & CATCCCCTGCCTTTGTTCT & CATTTATGTTGCTGATCCAAAAA & Indel & 143 \\
\hline$V v C R Y 1$ & CCCACAGGGAGAATTTTTCA & TCCCCAGCTTCTAATGGGTA & Indel & 1 \\
\hline$V v F T$ & CTGTGGTTGACGATCACCTG & TGAAATGGCATGAACCTCAA & SNP & 409 \\
\hline
\end{tabular}

of the linkage groups according to the current Vitis chromosome nomenclature (Doligez et al., 2006).

GeNOME LENGTH AND MAP COVERAGE. The estimated genome length was calculated using the method of moment estimator, $E(G)=M(M-1) X / K$, where $M$ is the number of loci, $X$ is the maximum map distance among all locus pairs above LOD = 5.0 , and $\mathrm{K}$ is the number of locus pairs having LOD values $\geq$ 5.0 , identified through the Strong Linkage tab in Joinmap, with the default parameter for strong linkage set to LOD > 5.0 (Chakravarti et al., 1991; Hulbert et al., 1988). The 95\% confidence interval for genome length, $\mathrm{I}_{\alpha}(\mathrm{G})$, was calculated as in Gerber and Rodolphe (1994). The expected genome coverage of the map $\mathrm{E}\left(\mathrm{C}_{\mathrm{n}}\right)$ was calculated after Bishop et al. (1983). A LOD threshold of 5.0 and Kosambi map distances (cM) were used for all calculations. For further details on the equations used, see Riaz et al. (2004).

QTL ANALYSIs. Composite interval mapping (Zeng, 1994) was conducted using WinQTL Cartographer 2.5 (Basten et al., 2005). Permutation tests with 1000 permutations were conducted to determine the experiment-wise significance threshold (Doerge and Churchill, 1996). For each trait, the LOD corresponding to an experiment-wise type-I error rate of 5\% was chosen as the threshold to declare QTL significant. The maximum LOD score was used to estimate the individual QTL positions, and a one-LOD support interval for the confidence interval.

Candidate Gene mapping. Molecular markers were developed within seven candidate genes. Primers for the Vitis homologues of the FLOWERING LOCUS T (VvFt) were based on published sequence (Sreekantan and Thomas, 2006). Markers for phytochrome A $(V v P H Y A)$, phytochrome B $(V v P H Y B)$, phytochrome C $(V v P H Y C)$, phytochrome $\mathrm{E}$ $(V v P H Y E)$, cryptochrome $1(V v C R Y 1)$, and CONSTANS $(V v C O)$ were based on identification of their single putative homologues in the grape genome sequence (Jaillon et al., 2007). Constans is a part of a large gene family, and the Vitis homolog identified is highly similar to $C O$, a member of the Group I subfamily that contains $C O$ and COL1-5 (Griffiths et al., 2003). The $\mathrm{F}_{1}$ was screened to locate gene regions that were heterozygous for an insertion-deletion polymorphism and could be converted into a PCR-based marker and analyzed for length polymorphism as described for the SSRs above. Where heterozygous indels could not be found, heterozygous single nucleotide polymorphisms were scored in sequenced amplicons. For sequencing, PCR products were quantified, purified with SAP (Promega) and Exol (New England Biolabs, Ipswisch, MA), and sequencing was performed by the Cornell Life Sciences Core Sequencing Laboratory. Chromatograms were analyzed using Sequencer 4.1.4 (GeneCodes, Ann Arbor, MI). Primer pairs used in mapping candidate genes are listed in Table 1.

\section{Results}

Phenotypic analysis. The critical photoperiod for growth cessation was determined by identification of the photoperiod at which laterals ceased to emerge. Clonal replication of $V$. riparia, 'Seyval', and the $\mathrm{F}_{1}$ allowed assessment of the within-genotype variability for the timing of growth cessation. With the exception of $V$. riparia in the field environment (2001 and 2002), all genotypes displayed moderate within- and between-year variability for the timing of growth cessation (Fig. 2). In addition, comparison of the parental genotypes shows that plants in the greenhouse show greater variation (within and between clones) for the timing of growth cessation than do the same plants in the field (Fig. 2).

In the greenhouse experiment, the $F_{2}$ progeny showed transgressive variation in critical photoperiod for cessation of lateral emergence, and a similar frequency of critical photoperiod was observed across years in the greenhouse (Figs. 2 and 3). Several progeny had a critical photoperiod of $14 \mathrm{~h}$, which is longer than the $V$. riparia parent, and $80 \%$ to $90 \%$ had critical photoperiods of 13 and $12 \mathrm{~h}$. ANOVA indicated significant

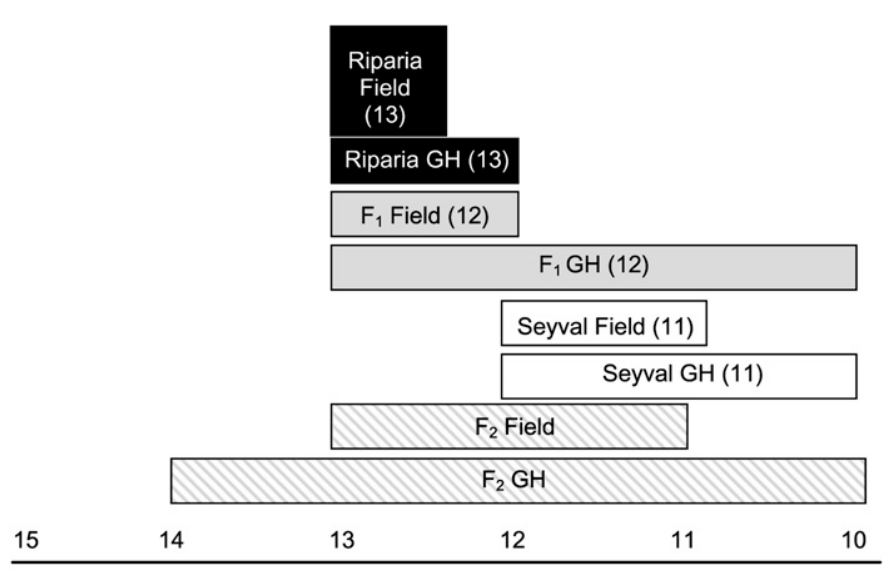

Critical photoperiod (h)

Fig. 2. Phenotypic variation for the critical photoperiod for growth cessation within Vitis riparia, Vitis hybrid 'Seyval' (Seyve-Villard 5-276), their $\mathrm{F}_{1}$, and the $F_{2}$ population in greenhouse $(\mathrm{GH})$ and field. Data for multiple years were pooled. The median value for $V$. riparia, 'Seyval', and their $\mathrm{F}_{1}$ is indicated in parenthesis. 


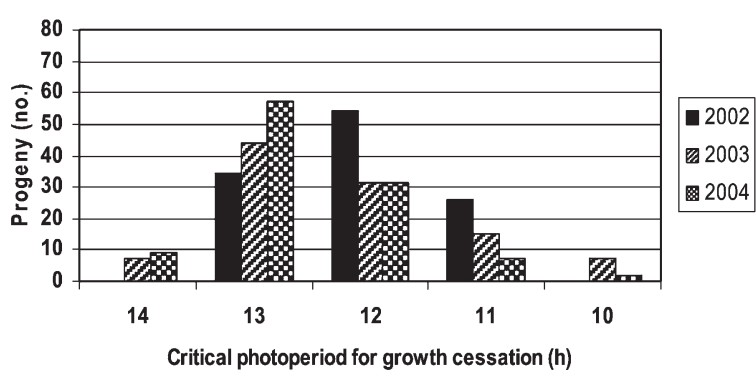

Fig. 3. Frequency distribution of the critical photoperiod for cessation of summer lateral emergence in $\mathrm{F}_{2}$ progeny of a cross between Vitis riparia and Vitis hybrid 'Seyval' (Seyve-Villard 5-276) grown at $25 / 20{ }^{\circ} \mathrm{C}$ (day/night) temperatures in the greenhouse experiment in 2002, 2003, and $2004(\mathrm{n}=113)$.

$(P<0.05)$ genotype effects and year effects for critical photoperiod in the greenhouse (Table 2).

In the field experiment, the $\mathrm{F}_{2}$ progeny also showed variation in the critical photoperiod for cessation of lateral emergence with a similar trend across years (Figs. 2 and 4). However, the distribution of the phenotypes differed from the greenhouse experiment. None of the progeny had a critical photoperiod of $14 \mathrm{~h}$, fewer individuals had a critical photoperiod of $13 \mathrm{~h}$, and a majority $(\approx 60 \%)$ had a critical photoperiod of $12 \mathrm{~h}$. Both genotype and year effects on critical photoperiod were significant $(P=0.079)$ (Table 3$)$. Values for the critical photoperiod were slightly and positively correlated across years in the field $(r=0.176, P=0.01)$, but there was no significant correlation between a genotype's critical photoperiod in the field and greenhouse experiments $(r=0.104, P=0.332)$. Additionally, critical photoperiod values for 2004 in the greenhouse were also slightly and positively correlated with those values from 2002 and $2003(r=0.212$ and $0.221, P=0.030$ and 0.027 , respectively); 2002 and 2003 greenhouse values were not significantly correlated $(r=0.101, P=0.309)$.

In addition to the identification of the critical photoperiod for growth cessation, the number of emerged laterals at each hour of photoperiod was scored. Although vine age and size increased during the study, the average number of summer laterals that developed at each hour of photoperiod between 15 and $12 \mathrm{~h}$ was similar in all 3 years in the greenhouse (Fig. 5). In the greenhouse treatment, ANOVA indicated significant $(P<$ $0.05)$ genotype effects for the number of laterals at 14-, 13-, and 12-h daylengths (Table 2). Year effects were significant $(P<0.05)$ for the number of laterals at 14- and 13-h daylengths. In the field, genotype effects across years were significant for the number of laterals at the 13-h daylength $(P=0.011)$, but not at the 12-h daylength; they were not significant for any trait in analyses of individual years (Table 3 ). Genotype $\times$ year

Table 2. Analyses of variance for the greenhouse experiment performed for the critical photoperiod for cessation of lateral emergence and the number of emerged laterals at 14-, 13-, or 12-h photoperiods in $\mathrm{F}_{2}$ progeny of the cross Vitis riparia $\times$ Vitis hybrid 'Seyval' (Seyve-Villard 5-276).

\begin{tabular}{|c|c|c|c|c|c|c|}
\hline & & & & & Mean squares & \\
\hline & & Mean squares & & Laterals at 14-h & Laterals at $13-\mathrm{h}$ & Laterals at $12-\mathrm{h}$ \\
\hline & df & $\overline{\text { Critical photoperiod }}$ & df & photoperiod & photoperiod & photoperiod \\
\hline$\overline{\text { Year }}$ & 2 & $7.844^{y}$ & 2 & $156.3^{y}$ & $22.78^{y}$ & 1.614 \\
\hline Genotype & 113 & $0.927^{y}$ & 114 & $6.2^{z}$ & $4.33^{\mathrm{y}}$ & $0.706^{z}$ \\
\hline
\end{tabular}

Fig. 4. Frequency distribution of the critical photoperiod for cessation of summer lateral emergence in $\mathrm{F}_{2}$ progeny of Vitis riparia $\times$ Vitis hybrid 'Seyval' (Seyve-Villard 5-276) grown in the field in Chanhassen, MN, in 2001 and $2002(n=95)$. Data are expressed as the mean of the three replicates.

Table 3. Analyses of variance for field experiment performed for the critical photoperiod for cessation of lateral emergence and the number of emerged laterals at 13 - or 12 -h photoperiods in $\mathrm{F}_{2}$ progeny of the cross Vitis riparia $\times$ Vitis hybrid 'Seyval' (SeyveVillard 5-276).

\begin{tabular}{lrccc}
\hline \multicolumn{5}{c}{ Analysis across years } \\
\hline & & \multicolumn{3}{c}{ Mean squares } \\
\cline { 3 - 5 } Source & df & $\begin{array}{c}\text { Critical } \\
\text { photoperiod }\end{array}$ & $\begin{array}{c}\text { Laterals at 13-h } \\
\text { photoperiod }\end{array}$ & $\begin{array}{c}\text { Laterals at 12-h } \\
\text { photoperiod }\end{array}$ \\
\hline Year & 1 & $8.854^{\mathrm{x}}$ & $443.97^{\mathrm{x}}$ & $9.69^{\mathrm{y}}$ \\
Genotype & 96 & $0.620^{\mathrm{z}}$ & $12.37^{\mathrm{y}}$ & 1.76 \\
Year $\times$ Genotype & 95 & 0.430 & 8.98 & 1.62 \\
& & \multicolumn{4}{c}{ Analyses by year } \\
& & \multicolumn{4}{c}{ Mean squares } \\
\cline { 3 - 5 } & & Critical & Laterals at 13-h Laterals at 12-h \\
Source & df & photoperiod & photoperiod & photoperiod \\
\hline Genotype (2001) & 95 & 0.603 & 6.29 & 0.851 \\
Genotype (2002) & 95 & 0.449 & $15.09^{y}$ & 2.529 \\
\hline
\end{tabular}

${ }^{\mathrm{z} P}<0.10$.

${ }^{\mathrm{y}} P<0.05$.

${ }^{\mathrm{x}} P<0.001$.

interactions were not significant, but year effects were $(P<$ $0.05)$.

Marker analysis AND linkage map CONSTRUCtion. Of the 205 primer pairs selected to provide genome coverage for map construction, $19(9.2 \%)$ did not amplify, 48 (23.4\%) did not segregate, $10(4.9 \%)$ produced more than two alleles, and 19 $(9.2 \%)$ amplified poorly in multiplex. The remaining 120 (56.1\%) were informative for mapping. Linkage analysis based on these SSR markers using a LOD of 5.0 resulted in 21 linkage groups and four unlinked markers (Fig. 6). Comparison with the integrated Vitis map confirmed that all linkage groups were covered, but LG 8 and LG 18 were fragmented into two groups each (Doligez et al., 2006). Under less stringent criteria, LG 8 and LG 18 could be joined into single groups, using LOD 2.0 and 3.0, respectively.

Four markers (VMCNG2H1, UDV109, VMC3B10, and VMC5G6) could not be grouped at LOD 5.0. Markers VMCNG2H1 (LG 11) and VMC3B10 (LG 2) likely were ungrouped because of their significant segregation distortion $(P<0.01)$. 


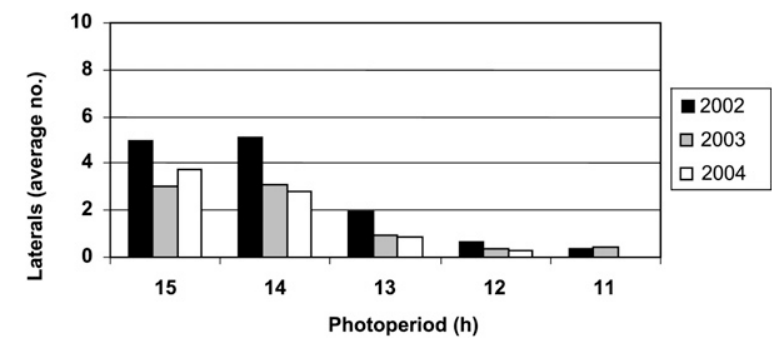

Fig. 5. Average number of summer laterals initiated for $\mathrm{F}_{2}$ progeny of Vitis riparia $\times$ Vitis hybrid 'Seyval' (Seyve-Villard 5-276) in each summer at each $1 \mathrm{~h}$ of photoperiod grown at $25 / 20{ }^{\circ} \mathrm{C}$ (day/night) temperatures in the greenhouse experiment in 2002, 2003, and $2004(\mathrm{n}=113)$.

Segregation distortion at VMC3B10 was the most extreme, with only homozygotes for the 'Seyval' allele recovered in the $\mathrm{F}_{2}$. According to the integrated map, UDV-109 (LG 2) is about $20 \mathrm{cM}$ from the nearest marker on our map, therefore a high rate of recombination may be the cause of its failure to group (Doligez et al., 2006). According to the assembled grape genome sequence, UDV109 and VMC3b10 are both located on LG $2, \approx 3.5 \mathrm{Mb}$ apart (Jaillon et al., 2007). Interestingly, VMCNG2H1 and VMC5G6 cannot be assigned unequivocally to positions on linkage groups in the current genome assembly.

Map Length AND Coverage. The estimated genome length was $1784 \mathrm{cM}$, with a $95 \%$ confidence interval of 1579.82 to $2048.78 \mathrm{cM}$. The combined length of the 21 linkage groups was $871 \mathrm{cM}$, providing an estimated genome coverage of $83.7 \%$. The average distance between markers was $8.4 \mathrm{cM}(\mathrm{SD}=6.6)$. The average linkage group size was $46.4 \mathrm{cM}$, with individual linkage groups ranging in size from $22 \mathrm{cM}$ (groups 6 and 15) to $76 \mathrm{cM}$ (group 10) (Table 4).

There were six gaps greater than $20 \mathrm{cM}$ on this map, on LGs $3,4,10,11,17$, and 19. Within these intervals, additional SSR markers were tested: six were monomorphic and two failed to amplify. In addition, there were eight gaps greater than $20 \mathrm{cM}$ relative to the framework map (Doligez et al., 2006). Efforts were made to fill these gaps, but the twenty tested markers in these intervals either failed to group, failed to amplify, or were monomorphic.

The map contained 95 markers in common with the framework map, and marker order was highly conserved (Doligez et al., 2006). Several potential inversions are noted in Fig. 6 on LGs 1, 2, 6, 8, and 16. Only two of these inverted loci (on LG 16; VMC1e11 and VMC3g11) can be attributed to segregation distortion and close proximity, which can complicate the determination of marker order. The remaining inverted loci did not show segregation distortion and may represent artifacts or real differences between the $V$. riparia genome structure and the framework maps.

Chromosomal-scale Segregation distortion. Of the informative markers, 25\% (29) showed significant departure from the Mendelian expectation of segregation of 1:2:1 $(P<$ $0.01)$. These markers were included in the analysis because they did not disrupt marker order, and all but three of the markers with segregation distortion were clustered on specific linkage groups. They formed clusters ( $>3$ consecutive loci) on the upper arm of LG 5, the center of LG 16, and the entire length of LG 7, LG 11, and LG 15 (Fig. 6). The skew in allele frequency could be determined on each linkage group, with overrepresentation of the $V$. riparia allele on LG 5, LG 7, and LG16, and the 'Seyval' allele on LG 11 and LG 15.
Mapping OF CANdidate Genes. $V v P H Y A, V v P H Y B$, $V v P H Y C, V v P H Y E, V v C O$, and $V v C R Y 1$ were mapped successfully in the $F_{2}$ population (Fig. 1, Table 1). Each mapped to a different linkage group, except $V v P H Y A$ and $V v C O$, which both mapped to LG 14, 51cM apart. The Flowering Locus $T$ homolog $(V v F T)$ (Sreekantan and Thomas, 2006) could not be mapped due to extreme segregation distortion $\left(\chi^{2}=28.3\right)$. In the $\mathrm{F}_{2}$ population, $43.3 \%$ of the progeny were homozygous for the 'Seyval' allele, $47.5 \%$ were heterozygous, and only $9.2 \%$ were homozygous for the $V$. riparia allele. In an effort to place this locus on the map in silico through comparison with the grape genome sequence, the gene was found on ML8X scaffold 409, which could not be assigned to a chromosome in the current genome assembly (Jaillon et al., 2007).

QTL ANALYSIS. QTL analysis was performed for the number of expanded laterals at each 1-h decline in photoperiod and the critical photoperiod for lateral growth cessation in the field and controlled greenhouse environment. A single QTL of major effect was identified in each of the two critical photoperiod experiments (field and greenhouse); however, the locations of the QTL differed by growing environment. In the greenhouse, where noninducing temperatures were maintained, a QTL on LG 13 explained $80.0 \%$ to $96.6 \%$ of the phenotypic variance (Table 5, Fig. 6). In the field, where vines experienced more disease pressure, natural fluctuations in temperature and rainfall, and a naturally decreasing photoperiod, a QTL on LG 11 explained $85.4 \%$ to $94.3 \%$ of phenotypic variance (Table 6, Fig. 6).

The QTL for critical photoperiod in the greenhouse overlapped with the QTL for the number of laterals in the greenhouse in the longest photoperiod scored $(14 \mathrm{~h})$. The QTL for growth cessation in the field colocated with the number of laterals in the field at the 12-h photoperiod in 2002 and the number of laterals in the greenhouse at the 13-h photoperiod in 2002. Many other QTL for the number of laterals at various photoperiods were identified (Tables 5 and 6), but colocated QTL were identified on LG 17 (field laterals at $12 \mathrm{~h}$ in 2001 and field laterals at $13 \mathrm{~h}$ in 2001) and LG 15 (field lateral at $12 \mathrm{~h}$ in 2002, greenhouse laterals at $12 \mathrm{~h}$ in 2002, greenhouse laterals at $12 \mathrm{~h}$ in 2004). The effect of these QTL ranged from $20 \%$ to $75 \%$. Candidate genes selected for their putative relationship to terminal budset and dormancy induction did not colocalize with the growth cessation QTL.

\section{Discussion}

COMPARISON WITH OTHER LINKAGE MAPS. The percentage of polymorphic markers $(76.6 \%)$ in this study is within the range reported for other Vitis maps $(55.8 \%$ to $88.4 \%$ ) (Adam-Blondon et al., 2004; Fischer et al., 2004; Grando et al., 2003; Lowe and Walker, 2006; Mandl et al., 2006). With a combined length of $871 \mathrm{cM}$, this is one of the smallest maps in grape, as maps range in length from 756 to 1639 cM (Doucleff et al., 2004; Grando et al., 2003). Our genome size estimation of $1784 \mathrm{cM}$ is within the range for grapes, from 1468.7 for $V$. vinifera 'Ramsey' (Lowe and Walker, 2006) to 2385 for $V$. vinifera 'Riesling' (Riaz et al., 2004). The size of the maximum distances between markers was $33.31 \mathrm{cM}$, similar to values in a map of Vitis champinii $\times V$. riparia (Lowe and Walker, 2006) and lower than those found by Riaz et al. (2004) for the cross $V$. vinifera 'Riesling' $\times V$. vinifera 'Cabernet Sauvignon'.

The percentage of loci showing segregation distortion $(25 \%)$ was higher in this cross than in any published reports thus far. 

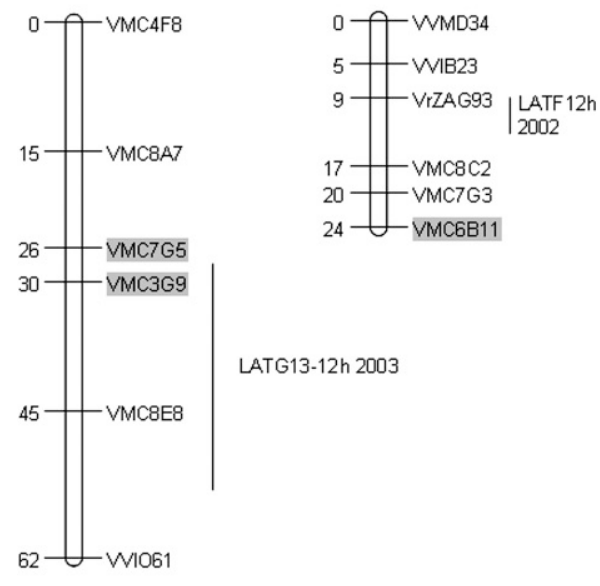

LATG13-12h 2003

5

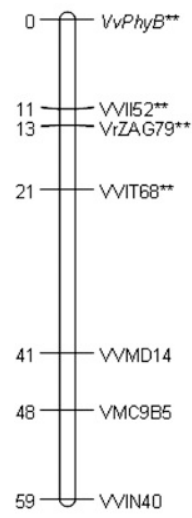

9

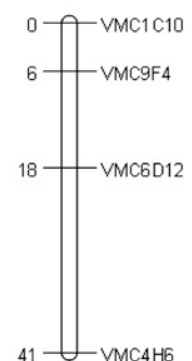

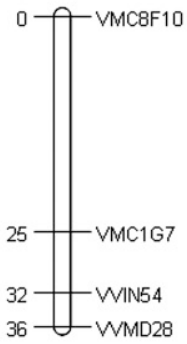

7

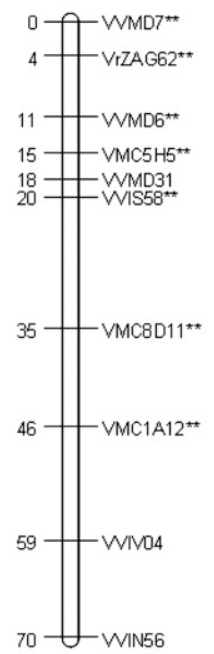

11

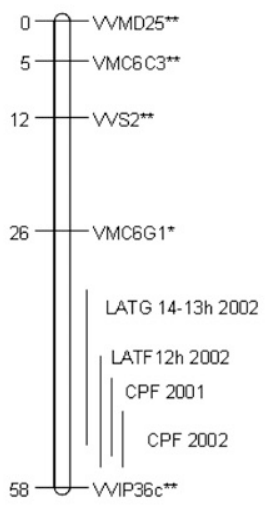

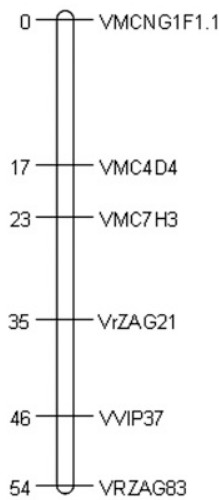

$8 \mathbf{a}$

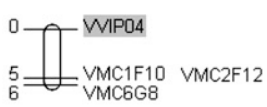

$8 b$

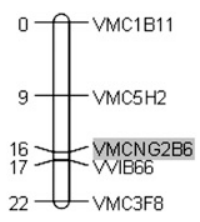

12

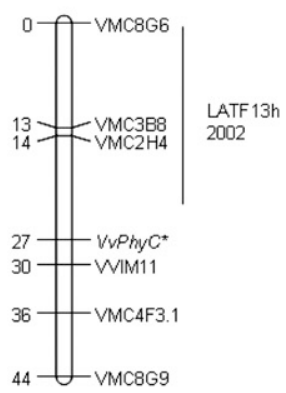

For $V$. vinifera crosses, the range commonly is between $7 \%$ and $11 \%$ (AdamBlondon et al., 2004; Doligez et al., 2006). However, both interspecific and intraspecific crosses that include wild species have a higher frequency of markers with segregation distortion, in the range of $16 \%$ to 22\% (Grando et al., 2003; Lowe and Walker, 2006). In our population, almost all of the segregation distortion occurred on a chromosomal scale, with contiguous markers consistently skewed toward 'Seyval' or V. riparia alleles. Segregation distortion may be attributed to several sources. Competition or selection can occur at several stages in reproduction through gametophytic factors such as pollen lethality, pollen-tube competition, or selective fertilization, selective elimination of zygotes, and structural rearrangements (Taylor and Ingvarsson, 2003). However, it is not known which of these factors caused the high segregation distortion observed in this population.

Genetic ARChitecture OF GROWTH CESSATION. Comparison of parental replicates revealed a significant amount of variation among clones in the precise timing of growth cessation. For example, although the majority (3/4) of $V$. riparia clones in the greenhouse had a critical photoperiod of $13 \mathrm{~h}$, one clone did not cease lateral emergence until the 12 -h photoperiod. This variation between clones of the same genotype indicates the complexities of measuring growth cessation in grapevines and suggests that though cessation of lateral emergence can be informative and heritable, it can be affected by a shoot's growth habit (drooping or bending change apical dominance effects) and environmental variation other than photoperiod and temperature. Studies of growth cessation in woody species such as poplar and birch monitor the formation of the terminal bud, a phenotype that does not occur in grapevine shoots. Despite differences in shoot morphology, in most woody species, growth cessation precedes dormancy induction, allowing redirection of resources to acclimation and dormancy processes and it is therefore a useful indicator phenotype for photoperiod sensitivity despite its inherent variability.

Previous segregation data suggested that short day-induced growth cessation is controlled by a single dominant gene or small family of genes (Fennell et al., 2005). Through QTL analysis of the greenhouse experiment, we identified a QTL that explained $80 \%$ to $96 \%$ of the phenotypic variance for the critical photoperiod for growth cessation. We conclude that

Fig. 6. Continued on next page. 

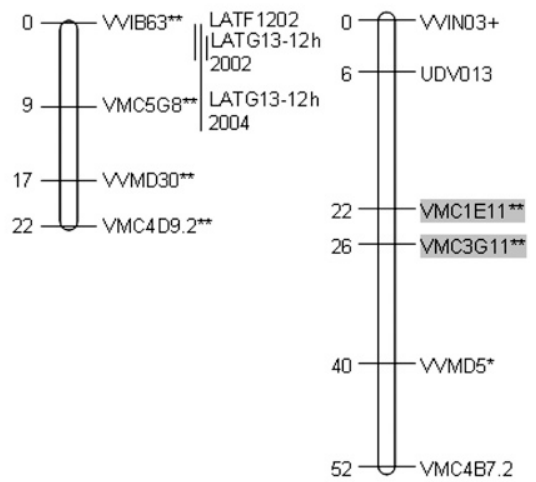

17

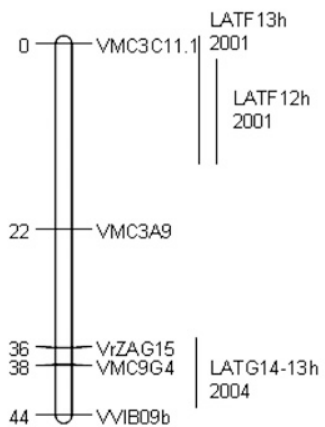

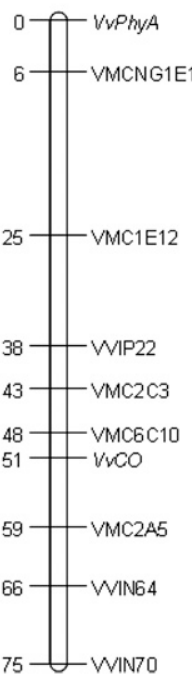

$18 \mathrm{a}$
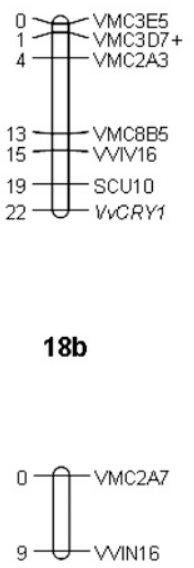

16

19

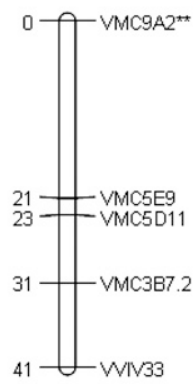

Fig. 6. Genetic map of $\mathrm{F}_{2}$ population derived from Vitis riparia $\times$ Vitis hybrid 'Seyval' (Seyve-Villard 5-276); LATF $=$ QTL for lateral cessation in field, $\mathrm{LATG}=\mathrm{QTL}$ for lateral cessation in greenhouse, $\mathrm{CPF}=\mathrm{QTL}$ for critical photoperiod in the field, $\mathrm{CPG}=\mathrm{QTL}$ for critical photoperiod in the greenhouse. A plus sign $(+)$ indicates that a locus maps to different linkage group in the Vitis vinifera framework map (Doligez et al., 2006). A grey box indicates that the marker order differs from the $V$. vinifera framework map; An asterisk indicates $\chi^{2}$ for segregation distortion $(P=0.01)$, and a double asterisk indicates $\chi^{2}$ for segregation distortion $(P=0.001)$.

In contrast to plants in the greenhouse experiment, plants in the field experienced naturally decreasing photoperiods in combination with natural variation in rainfall, temperature, ultraviolet light, and other environmental factors. Consequently, the growth cessation QTL on LG 11 , which explains $85.4 \%$ to $94.3 \%$ of phenotypic variance, cannot be ascribed to a particular environmental cue. Different QTL in the field and greenhouse are consistent with the lack of correlation we observed between a genotype's critical photoperiod in the two environments and overall differences in phenotypic distributions across treatments. This suggests that the QTL for growth cessation in the field encompasses a gene or genes for response to a nonphotoperiodic cue or perhaps a combination of environmental cues that may include a photoperiod component.

The absence of the extremely early growth cessation phenotype in the $F_{2}$ in the field suggests that permissive growing conditions could suppress or slow the rate of the early photoperiod response. A similar phenomenon was observed in poplar: genetic differences in photoperiodic responses played only a small role in explaining differences in the timing of bud set in the field, even in photoperiodsensitive ecotypes (Chen et al., 2002). More specifically, higher temperatures alter photoperiod response in several species. In bay willow (Salix pentandra), temperatures of $21{ }^{\circ} \mathrm{C}$ are sufficient to delay the onset of dormancy (Junttila, 1980). In strawberry (Fragaria vesca), a temperature increase of 3 ${ }^{\circ} \mathrm{C}$ decreased the critical photoperiod for flowering by $2 \mathrm{~h}$ (Heide and

this QTL mediates growth cessation in response to photoperiod. The presence of a QTL of major effect is consistent with studies in other woody species; major effect QTL have been reported for growth rhythm in Pinus sylvestris (Yazdani et al., 2003), bud set in P. sylvestris (Hurme et al., 2000), spring bud flush in Salix viminalis (Tsarouhas et al., 2003), and spring bud flush in poplar (Populus trichocarpa $\times P$. deltoides) (Bradshaw and Stettler, 1995). Although phenological traits are biologically complex and often quantitative, it is clear that phenotypes can be greatly influenced by genes of major effect. QTL of smaller effect also may affect growth cessation in this population, but our population size and marker density were insufficient for their detection, particularly if they interact with environmental variation.
Sonsteby, 2007). Similarly, in Prunus species, growth cessation was suppressed under the inducing photoperiod at high temperature $\left(2{ }^{\circ} \mathrm{C}\right)$ (Heide, 2008). This suggests that a thermosensitive pathway in plants can override photoperiod cues in developmental transitions, although the molecular mechanism has not been identified. In addition to differences in day and night temperatures between the field and greenhouse, the greenhouse experiments could have had greater temperature and light microenvironmental variation. For example, root temperatures likely fluctuated more in the greenhouse because of the fixed soil volume equilibrating with air temperature and daily cooling caused by watering.

Growth cessation occurred more synchronously in the field, but we have no evidence the cue for growth cessation is 
photoperiod alone in this environment. Whereas temperature, water status, and nutrient availability were controlled in the greenhouse experiment, growth cessation under field conditions could have been induced by any number of environmental

Table 4. Summary statistics for the Vitis riparia $\times$ Vitis hybrid 'Seyval' (Seyve-Villard 5-276) map. Estimated genome length and expected map coverage were calculated with map distances based on the Kosambi mapping function and logarithm of odds (LOD) of 5.0 .

\begin{tabular}{lc}
\hline Markers tested (no.) & 205 \\
Markers monomorphic in $\mathrm{F}_{2}$ (no.) & 48 \\
Markers with poor amplification (no.) & 19 \\
Markers producing multiple bands (no.) & 10 \\
Markers for mapping (no.) & 115 \\
Linked markers (no.) & 111 \\
Unlinked markers (no.) & 4 \\
Strong linkages between pairs (no.) & 230 \\
Maximum observed map distance (cM) & 31.311 \\
Estimated genome length (cM) & 1,784 \\
95\% confidence interval (cM) & $(1,579.82,2,048.78)$ \\
Expected map genome coverage (\%) & 83.7 \\
Average distance between markers (cM) & 8.4 \\
\hline
\end{tabular}

cues in addition to photoperiod, including drought, nutrient availability, or exposure to low, nonfreezing temperatures (Arora et al., 2003). Rainfall was sufficient in 2001 and 2002, making drought stress unlikely, although differences in microclimates across the $8 \times 125$-m vineyard or slight drought stress cannot be excluded as a source of variation. Infection of shoot tips in the field by downy mildew (Plasmopara viticola) was observed, especially in the wetter 2002 season, which may also have affected growth cessation. The greater synchrony in the field could be due to a synergistic response to daylength with temperature and other environmental factors that affect the rate of growth cessation.

The low temperature induction of growth cessation of the $V$. riparia and 'Seyval' parents has not been examined. However, in 2001 and 2002, low night temperatures of $10^{\circ} \mathrm{C}$ occurred occasionally during the 14-h photoperiod (August) and regularly during the 13- to 12-h photoperiod (September). Dormancy induction by low, nonfreezing temperatures has been observed in other woody species, such as birch, apple, pear, raspberry, and dogwood (Heide and Prestrud, 2005; Junttila et al., 2003; Palonen, 2006; Svendsen et al., 2007). The field growth cessation QTL may represent a gene or genes involved in low, nonfreezing temperature-induced growth cessation. The presence of a major effect QTL in the field that is distinct from

Table 5. Location, significance, and effect of individual QTL for the critical photoperiod for growth cessation and the number of summer laterals at 14- to 12-h photoperiods in $\mathrm{F}_{2}$ progeny of the cross Vitis riparia $\times$ Vitis hybrid 'Seyval' (Seyve-Villard 5-276) under greenhouse conditions.

\begin{tabular}{|c|c|c|c|c|c|c|c|c|}
\hline \multirow[b]{2}{*}{ Trait } & \multirow[b]{2}{*}{ Year } & \multicolumn{4}{|c|}{ QTL location } & \multirow[b]{2}{*}{ LOD } & \multicolumn{2}{|c|}{ QTL effect } \\
\hline & & $\overline{L^{2}}$ & Peak (cM) & Nearest marker & Interval (cM) & & $R^{2}$ & $\mathrm{a}$ \\
\hline \multirow[t]{2}{*}{ Critical photoperiod } & 2002 & 13 & 34 & VMC9H4_2 & $2-34$ & 340 & 96.6 & -6.01 \\
\hline & 2003 & 13 & 34 & VMC9H4_2 & $34-38$ & 250 & 88.0 & -6.12 \\
\hline \multicolumn{9}{|l|}{ No. of summer laterals } \\
\hline Laterals at $14 \mathrm{~h}$ & 2002 & 13 & 8 & VMC3D12 & $2-14$ & 14.8 & 15.0 & -1.39 \\
\hline Laterals at $13 \mathrm{~h}$ & 2002 & 11 & 48 & VVIP36g & $36-56$ & 42.0 & 39.4 & -2.91 \\
\hline Laterals at $12 \mathrm{~h}$ & 2002 & 15 & 2 & VMC4D92 & $2-4$ & 42.8 & 51.2 & -1.62 \\
\hline Laterals at $12 \mathrm{~h}$ & 2003 & 1 & 37 & VMC8E8 & $27-55$ & 21.4 & 23.8 & 0.44 \\
\hline Laterals at $12 \mathrm{~h}$ & 2004 & 15 & 8 & VMD30 & $0-10$ & 75.3 & 75.4 & -1.27 \\
\hline
\end{tabular}

${ }^{\mathrm{z}} \mathrm{LG}=$ linkage group; Peak $=$ location of local logarithm of odds (LOD) maximum in cM from the top of the linkage group; Nearest maker $=$ microsatellite closest to the local LOD maximum; Interval = confidence interval of QTL position in cM from the top of the linkage group; LOD = local LOD maximum (only LODs above the $\alpha=0.05$ experiment-wise type-I error rate are reported as determined by 1000 permutations); $R^{2}=$ proportion of total phenotypic variance explained by QTL; a = estimate of the additive effect on the trait.

Table 6. Location, significance, and effect of individual QTL for the critical photoperiod for growth cessation and the number of summer laterals at 13 - and 12-h photoperiods in $\mathrm{F}_{2}$ progeny of the cross Vitis riparia $\times$ Vitis hybrid 'Seyval' (Seyve-Villard 5-276) in the field.

\begin{tabular}{|c|c|c|c|c|c|c|c|c|}
\hline \multirow[b]{2}{*}{ Trait } & \multirow[b]{2}{*}{ Year } & \multicolumn{4}{|c|}{ QTL location } & \multirow[b]{2}{*}{ LOD } & \multicolumn{2}{|c|}{ QTL effect } \\
\hline & & $\overline{\mathrm{LG}^{\mathrm{z}}}$ & Peak (cM) & Nearest marker & Interval (cM) & & $\mathrm{R}^{2}$ & $\mathrm{a}$ \\
\hline Critical photoperiod & 2001 & 11 & 48 & VVIP36g & $46-52$ & 443 & 85.4 & 0.40 \\
\hline Critical photoperiod & 2002 & 11 & 48 & VVIP36g & $48-54$ & 447 & 94.3 & 0.18 \\
\hline Laterals at $12 \mathrm{~h}$ & 2002 & 11 & 50 & VVIP36g & $46-56$ & 71 & 54.1 & -1.93 \\
\hline Laterals at $12 \mathrm{~h}$ & 2002 & 15 & 2 & VVMD30 & $0-4$ & 21.1 & 30.7 & -2.36 \\
\hline Laterals at $12 \mathrm{~h}$ & 2002 & 2 & 9 & VRZAG93 & $9-11$ & 10.2 & 10.8 & -0.49 \\
\hline Laterals at $13 \mathrm{~h}$ & 2002 & 12 & 17 & VVMC2h4 & $2-20$ & 17.4 & 15.7 & -1.58 \\
\hline
\end{tabular}

${ }^{\mathrm{z}} \mathrm{LG}=$ linkage group; Peak = location of local logarithm of odds (LOD) maximum in cM from the top of the linkage group; Nearest maker $=$ microsatellite closest to the local LOD maximum; Interval = confidence interval of QTL position in cM from the top of the linkage group; LOD = local LOD maximum (only LODs above the $\alpha=0.05$ experiment wise type-I error rate are reported as determined by 1000 permutations); $\mathrm{R}^{2}=$ proportion of total phenotypic variance explained by QTL; a = estimate of the additive effect on the trait. 
the photoperiod-related QTL in the greenhouse experiment suggests that grapevines have a second system for growth cessation, resulting in flexible developmental responses to variable cues such as rainfall or temperature and reliable cues like photoperiod. Further studies will be required to determine what temperatures are sufficient to induce growth cessation in $V$. riparia or 'Seyval'.

The identification of stable QTLs across years, coupled with low interannual correlations, merits additional discussion. Further inspection of the data suggests that extreme phenotypes seem to be largely responsible for what little correlation exists. Removal of the extreme observations yields substantially reduced, or even reversed, correlations between years within the field data, as well as within the greenhouse data. In contrast, exclusion of the intermediate observations resulted in greatly enhanced correlation values. The individuals with consistent but divergent phenotypes are also likely to explain the detection of consistent QTLs.

CANDidate Genes. The candidate genes tested were selected based on information from photoperiod response in other species, but none of the genes colocalized with the QTL for growth cessation in the field or greenhouse. Elements of photoperiodic pathways are conserved between annuals and woody species, although developmental targets vary (e.g., flowering or tuberization vs. growth cessation and dormancy induction). The photoperiod response in woody species relies on a functional phytochrome system, demonstrated by the reversibility of short day-induced bud set by night-break experiments in cottonwood (Howe et al., 1996) and overexpression of the oat PHYA in hybrid aspen (Populus tremula $\times$ P. tremuloides) (Olsen et al., 1997; Welling et al., 2002). A potential role for phytochrome B is suggested by the colocalization of $P H Y B 1$ and $P H Y B 2$ with QTL for bud set and growth cessation in poplar, although the underlying genes have not been identified (Chen et al., 2002). We eliminated several photoreceptor genes as determinants of photoperiod sensitivity in $V$. riparia, including the four phytochromes in Vitis (PHYA, $P H Y B, P H Y C$, and PHYE) and CRY1 and conclude that the causal gene resides downstream of the phytochrome genes.

In addition to regulating flowering time and tuberization in response to photoperiod in some annual species, the $C O N$ STANS/FLOWERING LOCUS T (CO/FT) regulatory module controls short day-induced growth cessation and bud set in aspen ( $P$. tremula) and norway spruce (Picea abies) through downregulation of FT transcripts under short days (Bohlenius et al., 2006; Gyllenstrand et al., 2007). Our Vitis homolog of $C O$ did not colocate with any QTL, and the Vitis FT homolog could not be mapped due to severe segregation distortion. However, the grape FT/TFL1 gene family contains at least four other genes that could serve as candidate genes (Carmona et al., 2007), and in arabidopsis (Arabidopsis thaliana), the CONSTANS family contains 17 genes (Griffiths et al., 2003). Many candidate genes are plausible, as other downstream genes continue to be identified, such as the MADS-box transcription factors shown to cosegregate with a nondormant (evergreen) mutant in peach (Prunus persica) (Bielenberg et al., 2008) and genes involved in hormone synthesis, such as the genes regulating short dayinduced reduction in gibberellins (Molmann et al., 2003).

The regions covered by the QTL are large, spanning about $25 \mathrm{cM}$ for the greenhouse QTL and $8 \mathrm{cM}$ for the field QTL. These regions are too large to narrow the field of candidate genes using available genome sequence, and finer scale mapping will be required to identify the genes underlying these QTL. The availability of the grape genome sequence and development of a large numbers of single nucleotide polymorphism (SNP) markers makes it possible to improve marker density for fine mapping.

We constructed a map for an $\mathrm{F}_{2}$ population from the cross $V$. riparia $\times$ 'Seyval' and identified a QTL responsible for the segregation of photoperiod-induced growth cessation, as well as a separate field QTL for growth cessation that suggests environmental factors, which may include photoperiod, contribute to growth cessation in the field. This map will be useful for mapping additional traits such as cold hardiness and endodormancy requirements for budbreak. The development of climate-adapted grapevines is a major challenge for breeding programs, and a better understanding of the genetic control of growth cessation, identification of allelic variants with useful phenotypes, and the availability of robust associated markers will facilitate selection and introgression of photoperiod responsiveness from $V$. riparia into nonresponsive germplasm.

\section{Literature Cited}

Adam-Blondon, A.F., C. Roux, D. Claux, G. Butterlin, D. Merdinoglu, and P. This. 2004. Mapping 245 SSR markers on the Vitis vinifera genome: A tool for grape genetics. Theor. Appl. Genet. 109:10171027.

Alleweldt, G. and H. During. 1972. Influence of photoperiodism on growth and abscisic acid content in grapevines. Vitis 11:280-288.

Arora, R., L.J. Rowland, and K. Tanino. 2003. Induction and release of bud dormancy in woody perennials: A science comes of age. HortScience 38:911-921.

Basten, C.J., B.S. Weir, and Z.B. Zeng. 2005. WinQTL Cartographer v. 2.5, Dept. Statistics, North Carolina State Univ., Raleigh.

Bielenberg, D.G., Y. Wang, Z.G. Li, T. Zhebentyayeva, S.H. Fan, G.L. Reighard, R. Scorza, and A.G. Abbott. 2008. Sequencing and annotation of the evergrowing locus in peach Prunus persica (L.) Batsch reveals a cluster of six MADS-box transcription factors as candidate genes for regulation of terminal bud formation. Tree Genet. Genomes 4:495-507.

Bishop, D., C. Cannings, M. Skolnick, and J. Williamson. 1983. The number of polymorphic DNA clones required to map the human genome, p. 181-200. In: B.S. Weir (ed.). Statistical analysis of DNA sequence data. Marcel Dekker, New York.

Bohlenius, H., T. Huang, L. Charbonnel-Campaa, A.M. Brunner, S. Jansson, S.H. Strauss, and O. Nilsson. 2006. CO/FT regulatory module controls timing of flowering and seasonal growth cessation in trees. Science 312:1040-1043.

Bradshaw, H.D. and R.F. Stettler. 1995. Molecular-genetics of growth and development in Populus. IV. Mapping QTLs with large effects on growth, form, and phenology traits in a forest tree. Genetics 139:963-973.

Carmona, M.J., M. Calonje, and J.M. Martinez-Zapater. 2007. The FT/ TFL1 gene family in grapevine. Plant Mol. Biol. 63:637-650.

Chakravarti, A., L.K. Lasher, and J.E. Reefer. 1991. A maximumlikelihood method for estimating genome length using geneticlinkage data. Genetics 128:175-182.

Chen, T.H.H., G.T. Howe, and H.D. Bradshaw. 2002. Molecular genetic analysis of dormancy-related traits in poplars. Weed Sci. 50:232240.

Doerge, R.W. and G.A. Churchill. 1996. Permutation tests for multiple loci affecting a quantitative character. Genetics 142:285-294.

Doligez, A., A.F. Adam-Blondon, G. Cipriani, V. Laucou, D. Merdinoglu, C.P. Meredith, S. Riaz, C. Roux, P. This, and G. Di Gaspero. 2006. An integrated SSR map of grapevine based on five mapping populations. Theor. Appl. Genet. 113:369-382. 
Doucleff, M., Y. Jin, F. Gao, S. Riaz, A.F. Krivanek, and M.A. Walker. 2004. A genetic linkage map of grape, utilizing Vitis rupestris and Vitis arizonica. Theor. Appl. Genet. 109:1178-1187.

Fanizza, G., F. Lamaj, L. Costantini, R. Chaabane, and M.S. Grando. 2005. QTL analysis for fruit yield components in table grapes (Vitis vinifera). Theor. Appl. Genet. 111:658-664.

Fennell, A. and E. Hoover. 1991. Photoperiod influences growth, bud dormancy, and cold-acclimation in Vitis labruscana and V. riparia. J. Amer. Soc. Hort. Sci. 116:270-273.

Fennell, A., K. Mathiason, and J. Luby. 2005. Genetic segregation for indicators of photoperiod control of dormancy induction in Vitis species. Acta Hort. 689:533-539.

Fischer, B.M., I. Salakhutdinov, M. Akkurt, R. Eibach, K.J. Edwards, R. Topfer, and E.M. Zyprian. 2004. Quantitative trait locus analysis of fungal disease resistance factors on a molecular map of grapevine. Theor. Appl. Genet. 108:501-515.

Frewen, B.E., T.H.H. Chen, G.T. Howe, J. Davis, A. Rohde, W. Boerjan, and H.D. Bradshaw. 2000. Quantitative trait loci and candidate gene mapping of bud set and bud flush in Populus. Genetics 154:837-845.

Gerber, S. and F. Rodolphe. 1994. An estimation of the genome length of maritime pine (Pinus pinaster Ait). Theor. Appl. Genet. 88:289-292. Grando, M.S., D. Bellin, K.J. Edwards, C. Pozzi, M. Stefanini, and R. Velasco. 2003. Molecular linkage maps of Vitis vinifera L. and Vitis riparia Mchx. Theor. Appl. Genet. 106:1213-1224.

Griffiths, S., R.P. Dunford, G. Coupland, and D.A. Laurie. 2003. The evolution of CONSTANS-like gene families in barley, rice, and arabidopsis. Plant Physiol. 131:1855-1867.

Gyllenstrand, N., D. Clapham, T. Kallman, and U. Lagercrantz. 2007. A norway spruce FLOWERING LOCUS T homolog is implicated in control of growth rhythm in conifers. Plant Physiol. 144:248-257.

Heggie, L. and K.J. Halliday. 2005. The highs and lows of plant life: Temperature and light interactions in development. Intl. J. Dev. Biol. 49:675-687.

Heide, O.M. 2008. Interaction of photoperiod and temperature in the control of growth and dormancy of Prunus species. Scientia Hort. 115:309-314.

Heide, O.M. and A.K. Prestrud. 2005. Low temperature, but not photoperiod, controls growth cessation and dormancy induction and release in apple and pear. Tree Physiol. 25:109-114.

Heide, O.M. and A. Sonsteby. 2007. Interactions of temperature and photoperiod in the control of flowering of latitudinal and altitudinal populations of wild strawberry (Fragaria vesca). Physiol. Plant. 130:280-289.

Howe, G.T., G. Gardner, W.P. Hackett, and G.R. Furnier. 1996. Phytochrome control of short-day-induced bud set in black cottonwood. Physiol. Plant. 97:95-103.

Howe, G.T., P. Saruul, J. Davis, and T.H.H. Chen. 2000. Quantitative genetics of bud phenology, frost damage, and winter survival in an F2 family of hybrid poplars. Theor. Appl. Genet. 101:632-642.

Howe, G.T., W.P. Hackett, G.R. Furnier, and R.E. Klevorn. 1995. Photoperiodic responses of a northern and southern ecotype of black cottonwood. Physiol. Plant. 93:695-708.

Hulbert, S.H., T.W. Ilott, E.J. Legg, S.E. Lincoln, E.S. Lander, and R.W. Michelmore. 1988. Genetic analysis of the fungus, Bremia lactucae, using restriction fragment length polymorphisms. Genetics 120:947-958.

Hurme, P., M.J. Sillanpaa, E. Arjas, T. Repo, and O. Savolainen. 2000. Genetic basis of climatic adaptation in scots pine by Bayesian quantitative trait locus analysis. Genetics 156:1309-1322.

Jaillon, O., J.M. Aury, B. Noel, A. Policriti, C. Clepet, A. Casagrande, N. Choisne, S. Aubourg, N. Vitulo, C. Jubin, A. Vezzi, F. Legeai, P. Hugueney, C. Dasilva, D. Horner, E. Mica, D. Jublot, J. Poulain, C. Bruyere, A. Billault, B. Segurens, M. Gouyvenoux, E. Ugarte, F. Cattonaro, V. Anthouard, V. Vico, C. Del Fabbro, M. Alaux, G. Di Gaspero, V. Dumas, N. Felice, S. Paillard, I. Juman, M. Moroldo, S. Scalabrin, A. Canaguier, I. Le Clainche, G. Malacrida, E. Durand, G. Pesole, V. Laucou, P. Chatelet, D. Merdinoglu, M. Delledonne, M.
Pezzotti, A. Lecharny, C. Scarpelli, F. Artiguenave, M.E. Pe, G. Valle, M. Morgante, M. Caboche, A.F. Adam-Blondon, J. Weissenbach, F. Quetier, and P. Wincker. 2007. The grapevine genome sequence suggests ancestral hexaploidization in major angiosperm phyla. Nature 449:463-467.

Junttila, O. 1980. Flower bud differentiation in Salix pentandra as affected by photoperiod, temperature and growth-regulators. Physiol. Plant. 49:127-134.

Junttila, O., J. Nilsen, and B. Igeland. 2003. Effect of temperature on the induction of bud dormancy in ecotypes of Betula pubescens and Betula pendula. Scand. J. For. Res. 18:208-217.

Keller, M. and L.J. Mills. 2007. Effect of pruning on recovery and productivity of cold-injured Merlot grapevines. Amer. J. Enol. Viticult. 58:351-357.

Kosambi, D.D. 1943. The estimation of map distances from recombination values. Ann. Eugen. 12:172-175.

Kovacs, L.G., P.L. Byers, M.L. Kaps, and J. Saenz. 2003. Dormancy, cold hardiness, and spring frost hazard in Vitis amurensis hybrids under continental climatic conditions. Amer. J. Enol. Viticult. 54:8-14.

Krivanek, A., S. Riaz, and M.A. Walker. 2006. Identification and molecular mapping of $P d R 1$, a primary resistance gene to pierce's disease in Vitis. Theor. Appl. Genet. 112:1125-1131.

Li, C.Y., T. Puhakainen, A. Welling, A. Vihera-Aarnio, A. Ernstsen, O. Junttila, P. Heino, and E.T. Pavla. 2002. Cold acclimation in silver birch (Betula pendula). Development of freezing tolerance in different tissues and climatic ecotypes. Physiol. Plant. 116:478-488.

Lin, H. and M.A. Walker. 1997. Extracting DNA from cambium tissue for analysis of grape rootstocks. HortScience 32:1264-1266.

Lowe, K.M. and M.A. Walker. 2006. Genetic linkage map of the interspecific grape rootstock cross Ramsey (Vitis champinii) $\times$ Riparia Gloire (Vitis riparia). Theor. Appl. Genet. 112:1582-1592. Mandl, K., J.L. Santiago, R. Hack, A. Fardossi, and F. Regner. 2006. A genetic map of Welschriesling $\times$ Sirius for the identification of magnesium-deficiency by QTL analysis. Euphytica 149:133-144.

Molmann, J.A., A.T. Berhanu, S.K. Stormo, A. Ernstsen, O. Junttila, and J.E. Olsen. 2003. Metabolism of gibberellin A(19) is under photoperiodic control in Populus, Salix and Betula, but not in daylength-insensitive Populus overexpressing phytochrome A. Physiol. Plant. 119:278-286.

Olsen, J.E., O. Junttila, J. Nilsen, M.E. Eriksson, I. Martinussen, O. Olsson, G. Sandberg, and T. Moritz. 1997. Ectopic expression of oat phytochrome A in hybrid aspen changes critical daylength for growth and prevents cold acclimatization. Plant J. 12:1339-1350.

Palonen, P. 2006. Vegetative growth, cold acclimation, and dormancy as affected by temperature and photoperiod in six red raspberry (Rubus idaeus L.) cultivars. European J. Hort. Sci. 71:1-6.

Pierquet, P. and C. Stushnoff. 1978. Variation and breeding potential of some northern clones of Vitis riparia Michx. Fruit Var. J. 32:74-84.

R Development Core Team. 2007. R: A language and environment for statistical computing. R Foundation for Statistical Computing, Vienna, Austria.

Riaz, S., G.S. Dang1, K.J. Edwards, and C.P. Meredith. 2004. A microsatellite marker based framework linkage map of Vitis vinifera L. Theor. Appl. Genet. 108:864-872.

Sreekantan, L. and M.R. Thomas. 2006. VvFT and VvMADS8, the grapevine homologues of the floral integrators $F T$ and $S O C 1$, have unique expression patterns in grapevine and hasten flowering in arabidopsis. Funct. Plant Biol. 33:1129-1139.

Svendsen, E., R. Wilen, R. Stevenson, R.S. Liu, and K.K. Tanino. 2007. A molecular marker associated with low-temperature induction of dormancy in red osier dogwood (Cornus sericea). Tree Physiol. 27:385-397.

Taylor, D.R. and P.K. Ingvarsson. 2003. Common features of segregation distortion in plants and animals. Genetica 117:27-35.

Tsarouhas, V., U. Gullberg, and U. Lagercrantz. 2003. Mapping of quantitative trait loci controlling timing of bud flush in Salix. Hereditas 138:172-178. 
Van Ooijen, J.W. and R.E. Voorrips. 2001. JoinMap ${ }^{\circledR}$ version 3.0: Software for the calculation of genetic linkage maps. Plant Research International, Wageningen, The Netherlands.

Vezzulli, S., M. Troggio, G. Coppola, A. Jermakow, D. Cartwright, A. Zharkikh, M. Stefanini, M.S. Grando, R. Viola, A.F. Adam-Blondon, M. Thomas, P. This, and R. Velasco. 2008. A reference integrated map for cultivated grapevine (Vitis vinifera L.) from three crosses, based on 283 SSR and 501 SNP-based markers. Theor. Appl. Genet. 117:499-511.

Wake, C.M.F. and A. Fennell. 2000. Morphological, physiological and dormancy responses of three Vitis genotypes to short photoperiod. Physiol. Plant. 109:203-210.
Welling, A., T. Moritz, E.T. Palva, and O. Junttila. 2002. Independent activation of cold acclimation by low temperature and short photoperiod in hybrid aspen. Plant Physiol. 129:16331641.

Wolpert, J.A. and G.S. Howell. 1986. Effect of night interruption on cold acclimation of potted Concord grapevines. J. Amer. Soc. Hort. Sci. 111:16-20.

Yazdani, R., J.E. Nilsson, C. Plomion, and G. Mathur. 2003. Marker trait association for autumn cold acclimation and growth rhythm in Pinus sylvestris. Scand. J. For. Res. 18:29-38.

Zeng, Z.B. 1994. Precision mapping of quantitative trait loci. Genetics 136:1457-1468. 
Supplemental Table 1. Identity, multiplex, linkage group, and PCR parameters for 120 SSR markers used in mapping in the Vitis riparia $\times$ Vitis hybrid 'Seyval' (Seyve-Villard 5-276) F $F_{2}$ population. An asterisk after the linkage group indicates the marker did not map at logarithm of odds $(\mathrm{LOD})=5.0$ in this population; the linkage group indicated is based on the previously published maps. An "s" in the multiplex column indicates that the locus was amplified in singleplex.

\begin{tabular}{lllll}
\hline Multiplex & Primer name and published source & Linkage group no. & Annealing temperature $\left({ }^{\circ} \mathrm{C}\right)$ & Primer used per $20-\mu \mathrm{L}$ reaction $(\mathrm{pmol})$ \\
\hline
\end{tabular}

\begin{tabular}{|c|c|c|c|c|}
\hline 1 & $\mathrm{VMC}^{2} 2^{\mathrm{z}}$ & 2 & 55 & 5 \\
\hline 1 & $\mathrm{VMC} \mathrm{D} 4^{\mathrm{y}}$ & 4 & 55 & 3 \\
\hline 1 & $\mathrm{VMC} 2 \mathrm{~A} 7^{\mathrm{z}}$ & 18 & 55 & 3 \\
\hline 2 & $\mathrm{VMC} 3 \mathrm{G}^{\mathrm{z}}$ & 1 & 55 & 3 \\
\hline 2 & $\mathrm{VMC} 5 \mathrm{H} 2^{z}$ & 8 & 55 & 3 \\
\hline 3 & SsrVrZAG67 $7^{x}$ & 10 & 55 & 4 \\
\hline 3 & VVS2w & 11 & 55 & 3 \\
\hline 3 & VMC3D12z & 13 & 55 & 4 \\
\hline 3 & VVIN64 ${ }^{v}$ & 14 & 55 & 5 \\
\hline 4 & $\mathrm{VMC} 3 \mathrm{~F} 8^{\mathrm{z}}$ & 8 & 55 & 6 \\
\hline 4 & VMC6G8 $8^{u}$ & 8 & 55 & 3 \\
\hline 4 & VrZAG15x & 17 & 55 & 5 \\
\hline 5 & $\mathrm{VMC} 4 \mathrm{H} 6^{\mathrm{y}}$ & 9 & 55 & 4 \\
\hline 5 & $\mathrm{VMC} \mathrm{C} 3^{\mathrm{u}}$ & 11 & 55 & 5 \\
\hline 5 & VMC $3 \mathrm{c} 11.1^{\mathrm{z}}$ & 17 & 55 & 3 \\
\hline 6 & VMC8G6 $6^{t}$ & 12 & 55 & 3 \\
\hline 6 & $\mathrm{VMC} 3 \mathrm{~B} 7.2^{\mathrm{z}}$ & 19 & 55 & 5 \\
\hline 7 & $\mathrm{VMC} \mathrm{G} 3^{\mathrm{s}}$ & 2 & 55 & 4 \\
\hline 7 & ${\text { VVIM } 43^{v}}^{v}$ & 6 & 55 & 3 \\
\hline 8 & VVMD6 $^{\mathrm{r}}$ & 7 & 55 & 3 \\
\hline 8 & $\mathrm{VMC} 3 \mathrm{~A} 9^{\mathrm{z}}$ & 17 & 55 & 5 \\
\hline 9 & VVMD25r & 11 & 55 & 3 \\
\hline 9 & $\mathrm{VMC} 3 \mathrm{~B} 8^{\mathrm{z}}$ & 12 & 55 & 3 \\
\hline 9 & VMC8G9 $9^{z}$ & 12 & 55 & 5 \\
\hline 9 & VMCNG1E1z & 14 & 55 & 3 \\
\hline 10 & VrZAG79x & 5 & 55 & 3 \\
\hline 10 & $\mathrm{VrZAG}^{\mathrm{z}}$ & 10 & 55 & 3 \\
\hline 11 & $\mathrm{VMC} 5 \mathrm{H} 5^{z}$ & 7 & 55 & 4 \\
\hline 11 & SsrVrZAG25 & 10 & 55 & 3 \\
\hline 11 & $\mathrm{VMC} \mathrm{B} 5^{\mathrm{z}}$ & 18 & 55 & 3 \\
\hline 12 & VMC6D12u & 9 & 55 & 3 \\
\hline 12 & VMC6C10 $10^{t}$ & 14 & 55 & 4 \\
\hline 12 & VMC9G4 ${ }^{q}$ & 17 & 55 & 5 \\
\hline 12 & SCU10VV & 18 & 55 & 3 \\
\hline 13 & VMC6B1 $11^{\mathrm{u}}$ & 2 & 55 & 6 \\
\hline 13 & $\mathrm{VMC} 2 \mathrm{~F} 12^{\mathrm{z}}$ & 8 & 55 & 3 \\
\hline 13 & VVIP36C & 11 & 55 & 3 \\
\hline 13 & $\mathrm{VMC} 9 \mathrm{H} 4.2^{\mathrm{q}}$ & 13 & 55 & 3 \\
\hline 14 & $\mathrm{VMC} 8 \mathrm{~F} 10^{\mathrm{z}}$ & 3 & 55 & 4 \\
\hline 14 & $\mathrm{VMC} \mathrm{H} 3^{\mathrm{s}}$ & 4 & 55 & 3 \\
\hline 14 & VMC6G1 ${ }^{z}$ & 11 & 55 & 4 \\
\hline 14 & VMC5G8z & 15 & 55 & 5 \\
\hline 15 & VMC9B5 9 & 5 & 55 & 3 \\
\hline 15 & $\mathrm{VMC} 1 \mathrm{C} 10^{\mathrm{z}}$ & 9 & 55 & 3 \\
\hline 15 & VVIB09v & 17 & 55 & 5 \\
\hline 15 & VMC3B10 & $2 *$ & 55 & 5 \\
\hline 16 & $\mathrm{VMC} 1 \mathrm{G} 7^{\mathrm{z}}$ & 3 & 55 & 6 \\
\hline 16 & VMC4F3.1 $1^{\mathrm{y}}$ & 12 & 55 & 5 \\
\hline 16 & VMC5G6.1z & $8^{*}$ & 55 & 3 \\
\hline 17 & VMC5G1.1z & 6 & 55 & 6 \\
\hline 17 & ${\text { VVIB } 63^{v}}^{v}$ & 15 & 55 & 3 \\
\hline 17 & VVIV16 & 18 & 55 & 2.5 \\
\hline 18 & VVIN78v & 10 & 55 & 3 \\
\hline 18 & VVIM11 $1^{\mathrm{v}}$ & 12 & 55 & 3 \\
\hline 18 & VMC4D9. $2^{\mathrm{t}}$ & 15 & 55 & 6 \\
\hline
\end{tabular}


Supplemental Table 1. Continued.

\begin{tabular}{|c|c|c|c|c|}
\hline Multiplex & Primer name and published source & Linkage group no. & Annealing temperature $\left({ }^{\circ} \mathrm{C}\right)$ & Primer used per $20-\mu \mathrm{L}$ reaction $(\mathrm{pmol})$ \\
\hline 19 & VMC7G5s & 1 & 55 & 3 \\
\hline 19 & $\mathrm{VMC} 8 \mathrm{~A} 7^{\mathrm{z}}$ & 1 & 55 & 3 \\
\hline 19 & $\mathrm{VMC} 2 \mathrm{G} 2^{\mathrm{z}}$ & 6 & 55 & 2.5 \\
\hline 19 & VrZAG62 ${ }^{x}$ & 7 & 55 & 4 \\
\hline 20 & VVIS58v & 7 & 55 & 3 \\
\hline 20 & $\mathrm{VMC} 1 \mathrm{E} 12^{\mathrm{z}}$ & 14 & 55 & 3 \\
\hline 21 & VMC4H5 & 6 & 50 & 4 \\
\hline 21 & $\mathrm{VMC} 1 \mathrm{~B} 11^{\mathrm{z}}$ & 8 & 50 & 3 \\
\hline 21 & VVIB66 ${ }^{\mathrm{v}}$ & 8 & 50 & 3 \\
\hline 21 & $\mathrm{VMC} \mathrm{F}^{\mathrm{q}}$ & 9 & 50 & 4 \\
\hline 22 & VVIH54v & 13 & 55 & 3 \\
\hline 22 & VVMD30 ${ }^{\mathrm{r}}$ & 15 & 55 & 4 \\
\hline 23 & $\mathrm{VMC} 2 \mathrm{~F} 10^{\mathrm{z}}$ & 6 & 59 & 2 \\
\hline 23 & $\mathrm{VMC} 2 \mathrm{H} 9^{z}$ & 6 & 59 & 2 \\
\hline 23 & VMC5E9 & 19 & 59 & 4 \\
\hline 24 & $\mathrm{VMC} 2 \mathrm{H} 4^{\circ}$ & 12 & 55 & 3 \\
\hline 24 & VVIP22v & 14 & 55 & 3 \\
\hline 24 & VVIN16 & 18 & 55 & 4 \\
\hline 25 & SSRVrZAG93 $^{x}$ & 2 & 50 & 6 \\
\hline 25 & VMC3D $7^{z}$ & 18 & 50 & 6 \\
\hline 25 & VMC9A2.19 & 19 & 50 & 6 \\
\hline 25 & VVIV33 $^{v}$ & 19 & 50 & 8 \\
\hline 26 & VVMD34 ${ }^{\mathrm{r}}$ & 2 & 52 & 6 \\
\hline 26 & $\mathrm{VMC} 1 \mathrm{~A} 12^{\mathrm{z}}$ & 7 & 52 & 6 \\
\hline 26 & UDV-063 $3^{\mathrm{n}}$ & 10 & 52 & 6 \\
\hline 26 & VMC3E $5^{z}$ & 18 & 52 & 6 \\
\hline 27 & ${\text { VVIB } 23^{v}}^{v}$ & 2 & 52 & 6 \\
\hline 27 & $\mathrm{VMCNG} \mathrm{B} 6^{\mathrm{z}}$ & 8 & 52 & 6 \\
\hline 27 & VVIN03v $^{v}$ & 16 & 52 & 8 \\
\hline 27 & VMCNG $2 \mathrm{~h} 1^{\mathrm{t}}$ & $11^{*}$ & 52 & 8 \\
\hline 28 & $\mathrm{VMC} 3 \mathrm{D} 7^{\mathrm{z}}$ & 10 & 56 & 6 \\
\hline 28 & UDV- $-013^{\mathrm{n}}$ & 16 & 56 & 8 \\
\hline 28 & $\mathrm{VMC} 2 \mathrm{~A}^{\mathrm{z}}$ & 18 & 56 & 6 \\
\hline 29 & VVIV04ㄴ & 7 & 50 & 7 \\
\hline 29 & VVIP04v & 8 & 50 & 4 \\
\hline 29 & UDV $-109^{\mathrm{n}}$ & $2 *$ & 50 & 8 \\
\hline 30 & VMC1E11 ${ }^{z}$ & 16 & 58 & 12 \\
\hline 30 & VMC5D11 & 19 & 58 & 12 \\
\hline 31 & VVIT68v & 5 & 50 & 12 \\
\hline 31 & $\mathrm{VMC} 3 \mathrm{G} 11^{\mathrm{z}}$ & 16 & 50 & 12 \\
\hline 32 & VVIP37"v & 4 & 58 & 6 \\
\hline 32 & VMC8D11 & 6 & 58 & 3 \\
\hline 32 & $\mathrm{VMC} 2 \mathrm{C} 3^{\mathrm{z}}$ & 14 & 58 & 4 \\
\hline 33 & VVIN40 & 5 & 58 & 10 \\
\hline 33 & VVIH01 ${ }^{v}$ & 10 & 58 & 3 \\
\hline 34 & $\mathrm{VMC} \mathrm{E} 8^{\mathrm{z}}$ & 1 & 50 & 10 \\
\hline 34 & VVIN54" & 3 & 50 & 3 \\
\hline 34 & VMCNG1F1.1 ${ }^{z}$ & 4 & 50 & 3 \\
\hline 35 & VVMD28 $8^{r}$ & 3 & 57 & 3 \\
\hline 35 & VVIP10 ${ }^{v}$ & 13 & 57 & 12 \\
\hline 36 & SsrVrZAG83 ${ }^{\mathrm{x}}$ & 4 & 56 & 2 \\
\hline 36 & $\mathrm{VVMD}^{\mathrm{m}}$ & 7 & 56 & 6 \\
\hline 36 & $\mathrm{VMC} 2 \mathrm{~A} 5^{\mathrm{z}}$ & 14 & 56 & 3 \\
\hline 37 & VMC4F8 ${ }^{t}$ & 1 & 52 & 3 \\
\hline 37 & VVII52v & 5 & 52 & 3 \\
\hline 38 & SsrVrZAG2 $1^{\mathrm{x}}$ & 4 & 59 & 6 \\
\hline 38 & VVIN56r & 7 & 59 & 6 \\
\hline
\end{tabular}


Supplemental Table 1. Continued.

\begin{tabular}{lcccc}
\hline Multiplex & Primer name and published source & Linkage group no. & Annealing temperature $\left({ }^{\circ} \mathrm{C}\right)$ & Primer used per 20- $\mu \mathrm{L}$ reaction $(\mathrm{pmol})$ \\
\hline $\mathrm{s}$ & VVIO61 $^{\mathrm{r}}$ & 1 & 55 & 6 \\
$\mathrm{~s}$ & VVMD14 $^{\mathrm{r}}$ & 5 & 55 & 6 \\
$\mathrm{~s}$ & VVMD31 $^{\mathrm{r}}$ & 7 & 56 & 6 \\
$\mathrm{~s}$ & VMC1F10 $^{\mathrm{z}}$ & 8 & 50 & 5 \\
$\mathrm{~s}$ & VVIN70 $^{\mathrm{v}}$ & 14 & 56 & 4 \\
$\mathrm{~s}$ & VMC4B7 $^{\mathrm{z}}$ & 16 & 55 & 8 \\
$\mathrm{~s}$ & VVMD5 $^{\mathrm{m}}$ & 16 & 55 & 6 \\
\hline
\end{tabular}

${ }^{\mathrm{z}}$ Adam-Blondon et al., (2004).

${ }^{y}$ Di Gaspero et al., (2000).

'Sefc et al., (1999).

"Thomas et al., (1993).

'Merdinoglu et al., (2005).

"Arroyo-Garcia and Martinez-Zapater (2004).

'National Center for Biotechnology Information (2009).

sPellerone et al., (2001).

${ }^{\mathrm{r}}$ Bowers et al., (1999).

${ }^{\mathrm{q}}$ Lefort and Roubelakis-Angelakis (2009).

${ }^{\mathrm{p}}$ Scott et al., (2000).

${ }^{\circ}$ Goto-Yamamoto et al., (2004).

${ }^{n}$ Di Gaspero et al., (2005).

${ }^{\mathrm{m}}$ Bowers et al., (1996).

\section{Literature Cited for Supplemental Table 1}

Adam-Blondon, A.F., C. Roux, D. Claux, G. Butterlin, D. Merdinoglu, and P. This. 2004. Mapping 245 SSR markers on the Vitis vinifera genome: A tool for grape genetics. Theor. Appl. Genet. 109:10171027.

Arroyo-Garcia, R. and J.M. Martinez-Zapater. 2004. Development and characterization of new microsatellite markers for grape. Vitis 43:175-178.

Bowers, J.E., G.S. Dangl, and C.P. Meredith. 1999. Development and characterization of additional microsatellite DNA markers for grape. Amer. J. Enol. Viticult. 50:243-246.

Bowers, J.E., G.S. Dangl, R. Vignani, and C.P. Meredith. 1996. Isolation and characterization of new polymorphic simple sequence repeat loci in grape (Vitis vinifera L.). Genome 39:628-633.

Di Gaspero, G., E. Peterlunger, R. Testolin, K.J. Edwards, and G. Cipriani. 2000. Conservation of microsatellite loci within the genus Vitis. Theor. Appl. Genet. 101:301-308.

Di Gaspero, G., G. Cipriani, M.T. Marrazzo, D. Andreetta, M.J.P. Castro, E. Peterlunger, and R. Testolin. 2005. Isolation of (AC)nmicrosatellites in Vitis vinifera $\mathrm{L}$. and analysis of genetic background in grapevines under marker assisted selection. Mol. Breed. 15:11-20. Goto-Yamamoto, N., H. Mouri, M. Azumi, and K.J. Edwards. 2004. Development of grape microsatellite markers and microsatellite analysis including oriental cultivars. Amer. J. Enol. Viticult. 57:105-108.
Lefort, F. and K.A. Roubelakis-Angelakis. 2009. The Greek Vitis Database. 4 Feb. 2009. <http://gvd.biology.uoc.gr/gvd/contents/ general-info/index.htm>.

Merdinoglu, D., G. Butterlin, L. Bevilacqua, V. Chiquet, A.F. AdamBlondon, and S. Decroocq. 2005. Development and characterization of a large set of microsatellite markers in grapevine (Vitis vinifera L.) suitable for multiplex PCR. Mol. Breed. 15:349-366.

National Center for Biotechnology Information. 2009. UniSTS: Integrating markers and maps. 4 Feb. 2009. <http://www.ncbi.nlm. nih.gov/sites/entrez? $\mathrm{db}=$ unists $>$.

Pellerone, F.I., K.J. Edwards, and M.R. Thomas. 2001. Grapevine microsatellite repeats: Isolation, characterisation and use for genotyping of grape germplasm from southern Italy. Vitis 40:179-186.

Scott, K.D., P. Eggler, G. Seaton, M. Rossetto, E.M. Ablett, L.S. Lee, and R.J. Henry. 2000. Analysis of SSRs derived from grape ESTs. Theor. Appl. Genet. 100:723-726.

Sefc, K.M., F. Regner, E. Turetschek, J. Glossl, and H. Steinkellner. 1999. Identification of microsatellite sequences in Vitis riparia and their applicability for genotyping of different Vitis species. Genome 42:367-373.

Thomas, M.R., S. Matsumoto, P. Cain, and N.S. Scott. 1993. Repetitive DNA of grapevine: Classes present and sequences suitable for cultivar identification. Theor. Appl. Genet. 86:173-180. 